\title{
Osteoconductivity and Biodegradability of Collagen Scaffold Coated with Nano- $\beta$-TCP and Fibroblast Growth Factor 2
}

\author{
Asako Ibara, ${ }^{1}$ Hirofumi Miyaji, ${ }^{1}$ Bunshi Fugetsu, ${ }^{2}$ Erika Nishida, ${ }^{1}$ Hiroko Takita, ${ }^{3}$ \\ Saori Tanaka, ${ }^{1}$ Tsutomu Sugaya, ${ }^{1}$ and Masamitsu Kawanami ${ }^{1}$ \\ ${ }^{1}$ Department of Periodontology and Endodontology, Hokkaido University Graduate School of Dental Medicine, N13 W7, \\ Kita-ku, Sapporo 060-8586, Japan \\ ${ }^{2}$ Hokkaido University Graduate School of Environmental Science, N10 W5, Kita-ku, Sapporo 060-0810, Japan \\ ${ }^{3}$ Support Section for Education and Research, Hokkaido University Graduate School of Dental Medicine, N13 W7, Kita-ku, \\ Sapporo 060-8586, Japan
}

Correspondence should be addressed to Hirofumi Miyaji; miyaji@den.hokudai.ac.jp

Received 18 January 2013; Revised 14 May 2013; Accepted 24 May 2013

Academic Editor: Shafiul Chowdhury

Copyright (C) 2013 Asako Ibara et al. This is an open access article distributed under the Creative Commons Attribution License, which permits unrestricted use, distribution, and reproduction in any medium, provided the original work is properly cited.

\begin{abstract}
Nanoparticle bioceramics have become anticipated for biomedical applications. Highly bioactive and biodegradable scaffolds would be developed using nanoparticles of $\beta$-tricalcium phosphate $(\beta$-TCP). We prepared collagen scaffolds coated by nano- $\beta$-TCP and fibroblast growth factor 2 (FGF2) and evaluated the effects on new bone augmentation and biodegradation. The collagen sponge was coated with the nano-TCP dispersion and freeze-dried. Scaffold was characterized by SEM, TEM, XRD, compressive testing and cell seeding. Subsequently, the nano- $\beta$-TCP/collagen scaffold, collagen sponge, and each material loaded with FGF2 were implanted on rat cranial bone. As a control, no implantation was performed. Nano-TCP particles were found to be attached to the fibers of the collagen sponge by SEM and TEM observations. Scaffold coated with nano-TCP showed higher compressive strength and cytocompatibility. In histological evaluations at 10 days, inflammatory cells were rarely seen around the residual scaffold, suggesting that the nano-TCP material possesses good tissue compatibility. At 35 days, bone augmentation and scaffold degradation in histological samples receiving nano- $\beta$-TCP scaffold were significantly greater than those in the control. By loading of FGF2, advanced bone formation is facilitated, indicating that a combination with FGF2 would be effective for bone tissue engineering.
\end{abstract}

\section{Introduction}

Tissue engineering strategies involving three major elements: cells, growth and differentiation factors, and natural or artificial scaffolds have been developed for use in various tissues of the human body. Scaffolds in regenerative medicine provide the base for repopulation and specialization of stem cells, blood vessels, and extracellular matrices [1]. In previous studies, bioceramic scaffolds such as calcium phosphate, hydroxyapatite (HA) [2,3], and bioactive glass [4] have been applied in various artificially synthesized forms in bone tissue engineering [5]. It was reported that the scaffold of $\beta$-tricalcium phosphate ( $\beta$-TCP) and bioceramic composites possessed mechanical integrity, microstructural properties, and biocompatibility. Furthermore, degradation of TCP was demonstrated when compared to the HA scaffold
[6-8], suggesting that regenerating cells and tissues may receive inorganic ions for osteogenesis. The $\beta$-TCP scaffold in combination with various growth factors has been shown to stimulate bone augmentation $[9,10]$. For clinical trials, bone graft substitutes using $\beta$-TCP have been used in the orthopedic and dental fields [11, 12].

Regenerative scaffolds require rapid replacement by reformed tissue in the healing site. Degradation of $\beta$-TCP has revealed, however, that the resorption rate of $\beta$-TCP is relatively slow compared to tissue regrowth. It was frequently demonstrated that a large amount of residual $\beta$ TCP material was surrounded by regenerated bone $[10,11]$. Low degradability of bioceramics including $\beta$-TCP has been reported in animal and human studies $[6,8,13,14]$, suggesting that aberrant healing using bioceramics will be increased by exposure to and contamination by residual materials. 
Recently, nanoparticle bioceramics have been introduced and expected to have a use for biomedical applications due to quantum size effects and a large surface area $[15,16]$. Scaffolds with nanomaterial exhibited higher compressive strength, degradation rate, osteoconductivity, and protein absorption compared to scaffolds of submicron bioceramics $[17,18]$. Although HA is a nonresorbable material, nanosized $\mathrm{HA}$ is resorbed in association with new bone formation [19]. Thus, high degradability as well as osteoconductivity might be provided to regenerative scaffolds for bone tissue engineering by the use of nanosized TCP. Replacement and maturation of engineered tissue are supposedly stimulated by a rapid remodeling process induced by nano-ceramics. When using synthetic nanoparticles as biomaterials, it is very important to regulate the aggregation/dispersion of nanoparticles. Nanoparticle of $\beta$-TCP as a biological scaffold have been combined with other material [20] and sintered for coagulation [18, 21]; however, dispersing effect will be insufficient. In this study, the easy regulatory process was performed; the biocompatible collagen sponge was immersed in an aqueous dispersion of nano- $\beta$-TCP using zwitterionic surfactants, for suppressing of nanosize particle agglutination $[22,23]$. This easy method may be widely used for clinical trials. In addition, morphology of the biomaterial surface strongly affected attachment to cells and tissue after implantation $[24,25]$. Nanostructure should be exposed at the surface of the base material. Early contact between regenerative cells or tissues and the nanosized effective factors will facilitate the tissue-reforming process. The nano-coating method will be developed for synthesizing a higher surface area of the scaffold and be conducive to novel bone-forming-related products.

Fibroblast growth factor-2 (FGF2) stimulates cell proliferation, migration, and differentiation associated with wound healing [26]. FGF2 also regulates proliferation of osteogenic cells, such as osteoblasts and bone marrow stromal cells, resulting in bone augmentation $[27,28]$ and periodontal regeneration [29]. Based on animal results, a clinical trial of multiwall defects in patients with periodontitis was performed [30]. Thus, we hypothesized that the nano $\beta$ TCP/collagen scaffold in combination with FGF2 might accelerate bone tissue healing. However, the relation of nano$\beta$-TCP and FGF2 use has not yet been investigated. The aim of the present study was to evaluate whether implantation of the nano- $\beta$-TCP/collagen scaffold with or without FGF2 loading induced bone augmentation in rat. We also examined the effect of nano $\beta$-TCP modifying on biodegradation.

\section{Materials and Methods}

2.1. Preparation of Collagen Sponge. Collagen sponge, an average porosity of $96 \%$, was provided by Olympus Terumo Biomaterials (Tokyo, Japan). Atelocollagen in a dilute $\mathrm{HCl}$ solution ( $\mathrm{pH}$ 3.0) was neutralized by adding concentrated phosphate buffer in $\mathrm{NaCl}$ to a final concentration of $0.1 \%$ collagen, $30 \mathrm{mM} \mathrm{Na} \mathrm{HPO}_{4}$, and $0.1 \mathrm{M} \mathrm{NaCl}$. This collagen solution was incubated at $37^{\circ} \mathrm{C}$ for $4 \mathrm{~h}$. The resulting fibrous precipitate was referred to as fibrillar collagen. Heatdenatured collagen was prepared from atelocollagen in a dilute $\mathrm{HCl}$ solution by heating at $60^{\circ} \mathrm{C}$ for $30 \mathrm{~min}$. A composite of fibrillar and heat-denatured collagen was prepared by mixing the two at a ratio of $9: 1(\mathrm{w} / \mathrm{w})$, respectively. This composite material was made into the form of a sponge by lyophilization at $-30^{\circ} \mathrm{C}$. This sponge was dehydrothermally cross-linked at $110^{\circ} \mathrm{C}$ for $2 \mathrm{~h}$ and used as a collagen sponge (Figure 1(a)).

\subsection{Preparation and Characterization of Nano $\beta-T C P / C o l-$} lagen Scaffold. $\beta$-TCP (average particle size: $2.3 \mu \mathrm{m}$ ) was provided by Tomita Pharmaceuticals (Naruto, Japan). Morphology of $\beta$-TCP particles was evaluated using a scanning electron microscope (SEM, S-4000, Hitachi, Tokyo, Japan) at an accelerating voltage of $10 \mathrm{kV}$ after coating with a thin layer of Pt-PD (Figure $1(\mathrm{~d})$ ). $\beta$-TCP particles were pulverized to nanosized particles using a pulverizer (Nanomizer, Yokohama, Japan). Nano $\beta$-TCP particles along with the surfactant sodium cholate $(0.2 \mathrm{wt} \%)$ were dispersed in distilled water. The particle size of nano-TCP was detected by SEM and particle size distribution analysis (LB-550, Horiba, Kyoto, Japan). Subsequently, the collagen sponge was immersed in a nano- $\beta$-TCP dispersion ( $1 \mathrm{wt} \%$ ) for $24 \mathrm{~h}$ at $10^{\circ} \mathrm{C}$. After rinsing in $70 \%$ ethanol and freeze-drying, the nano- $\beta$-TCP/collagen scaffold was configured (Figure 1(a)). Scaffold was characterized using SEM and transmission electron microscope (TEM, HD-2000, Hitachi, Tokyo, Japan) at $200 \mathrm{kV}$ acceleration voltage. The porosity of the scaffold was calculated according to the following equation: porosity $=100 \times(1-\rho 1 / \rho 2)$, where $\rho 1=$ bulk density and $\rho 2=$ theoretical density of the scaffold. The scaffold was also characterized using X-ray diffraction (XRD, RINT2000, Rigaku, Tokyo, Japan). Cu K $\alpha$ radiation at $40 \mathrm{kV}$ and $40 \mathrm{~mA}$ was used. Diffractograms were obtained from $2 \theta=10^{\circ}$ to $90^{\circ}$ with an increment of $0.02^{\circ}$, at a scanning speed of $4^{\circ} /$ minute. The compression test was performed using a universal testing machine (EZ-S, Shimadzu, Kyoto, Japan). The cross-head loading speed was set at $0.5 \mathrm{~mm} / \mathrm{min}$.

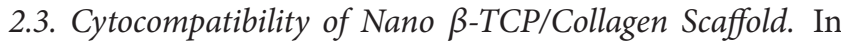
order to evaluate the cytocompatibility, nano- $\beta$-TCP/collagen scaffolds and collagen sponges were seeded with 1 $\times 10^{4}$ mouse osteoblastic MC3T3-E1 cells and cultured in humidified $5 \% \mathrm{CO}_{2}$ at $37^{\circ} \mathrm{C}$, using medium (MEM alphaGlutaMAX-I, Life Technologies, Grand Island, NY, USA) supplemented with 10\% fetal bovine serum (FBS, Qualified, Life Technologies) and 1\% antibiotics (Pen Strep, Life Technologies). After 24 and $48 \mathrm{~h}$ culture, cytotoxicity was detected by the cell counting kit-8 (CCK-8, Dojindo Laboratories, Kumamoto, Japan), following the manufacturer's instructions. Optical density was measured on a microplate reader (ETY-300, Toyo Sokki, Yokohama, Japan) using an absorbance of $450 \mathrm{~nm}$. Some samples were fixed in $2.5 \%$ glutaraldehyde in $0.1 \mathrm{M}$ sodium cacodylate buffer ( $\mathrm{pH} 7.4$ ) for $30 \mathrm{~min}$ and rinsed in cacodylate buffer solution. Scaffolds were then dehydrated in increasing concentrations of ethanol and analyzed by SEM.

2.4. FGF2 Implant Preparation. FGF2 (Fiblast spray 500, Kaken Pharmaceutical, Tokyo, Japan) was diluted with 


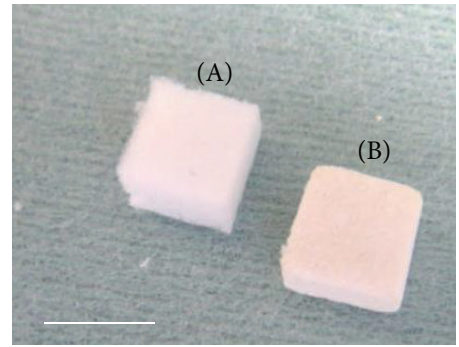

(a)

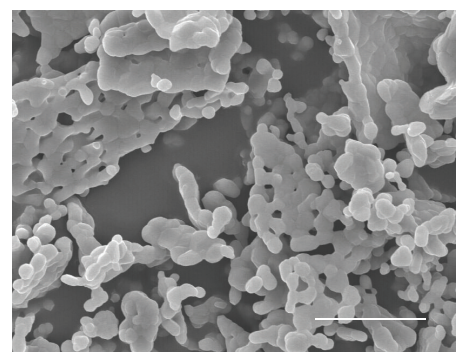

(d)

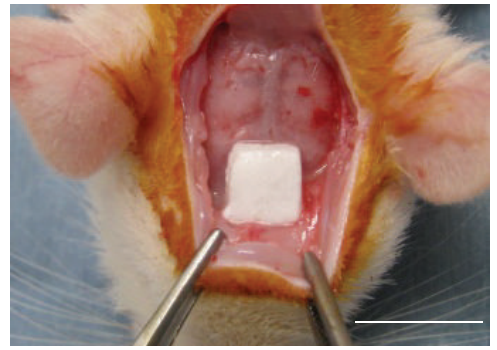

(b)

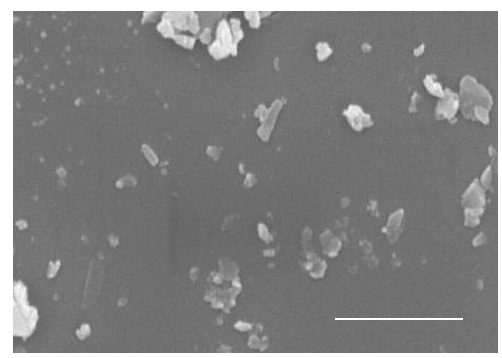

(e)

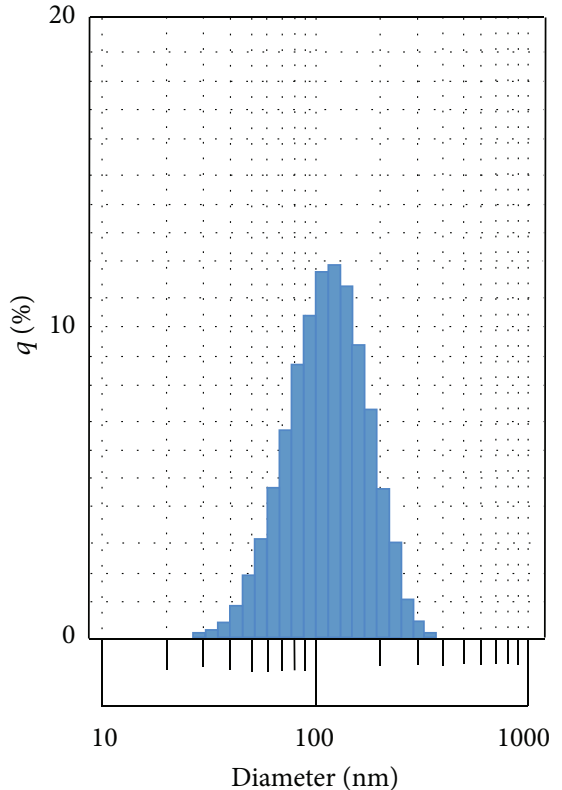

(c)

Figure 1: (a) Collagen sponge (A) and nano- $\beta$-TCP/collagen scaffold (B). (b) Surgical procedure: the samples were placed on the cranial bone. (c) Measurement of particle size distribution analysis for nano-TCP. (d) SEM micrograph of the $\beta$-TCP particles. (e) SEM micrograph of the nanopulverized $\beta$-TCP particles. Scale bars represent $5 \mathrm{~mm}$ (a), $10 \mathrm{~mm}$ (b), $10 \mu \mathrm{m}$ (d), and $1 \mu \mathrm{m}$ (e).

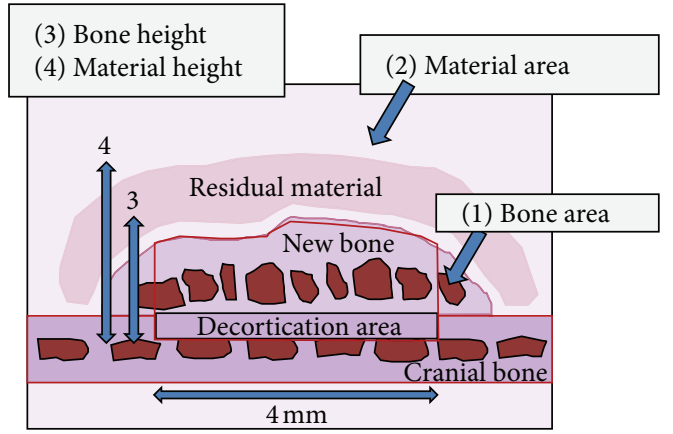

FIGURE 2: Schematic drawing of histomorphometric analysis. The frontal plane view indicating the following parameters: the area of newly formed bone (1), the area of residual material (2), the height of newly formed bone (3), and the height of residual material (4).

distilled water (Otsuka distilled water, Otsuka Pharmaceutical, Tokyo, Japan) to produce stock solution of $0.5 \mu \mathrm{g} / \mu \mathrm{L}$. In the FGF2-loading group, nano- $\beta$-TCP/collagen scaffold and collagen sponge (size $6 \times 6 \times 3 \mathrm{~mm}$ ) were injected with $100 \mu \mathrm{L}$ FGF2 solution (loading dose; $50 \mu \mathrm{g}$ ) under vacuum. In the other groups, each material received distilled water alone.

2.5. Surgical Procedure for Bone Forming Effect and Biodegradability of Scaffold. The experimental protocol followed the institutional animal use and care regulations of Hokkaido University (Animal Research Committee of Hokkaido University, Approval number 10-42). Forty-eight 10-week-old male Wistar rats weighing 190 to $210 \mathrm{~g}$ were given general anesthesia by inhalation of diethyl ether and intraperitoneal injections of $0.6 \mathrm{~mL} / \mathrm{kg}$ sodium pentobarbital
(Somnopenthyl, Kyoritsu Seiyaku, Tokyo, Japan), as well as a local injection of $2 \%$ lidocaine hydrochloride with 1:80,000 epinephrine (Xylocaine Cartridge for Dental Use, DentsplySankin K.K. Tokyo, Japan). After a skin incision was made in the scalp, a flap was made. Decortication of a $4 \mathrm{~mm}^{2}$ area was performed in front of the coronal suture in the cranial bone using a rotating round bur under water irrigation. Subsequently, four types of samples: nano- $\beta$-TCP/collagen scaffold, collagen sponge, and each material loaded with FGF2 were placed on the cranial bone with decortication (Figure 1(b)). As a control, no implantation was performed. Skin flaps were sutured (Softretch 4-0, GC, Tokyo, Japan) and tetracycline hydrochloride ointment (Achromycin Ointment, POLA Pharma, Tokyo, Japan) was applied to the wound.

2.6. Histological Procedure. Rats were euthanized using an overdose of diethyl ether and sodium pentobarbital $(2.0 \mathrm{~mL} / \mathrm{kg})$. Specimens were collected from the wound 10 and 35 days after surgery. The tissue blocks including the cranial bone and surrounding soft tissue were fixed in 10\% buffered formalin, decalcified in 10\% EDTA, embedded along the frontal plane in paraffin wax, and cut into $6 \mu \mathrm{m}$ sections located every $300 \mu \mathrm{m}$. Sections were prepared and stained with hematoxylin-eosin (HE) and Masson's trichrome.

2.7. Histomorphometric and Statistical Analysis. One section was taken for histomorphometric measurement from the midsection of the scaffold. The following measurements (Figure 2): the height and the area of both newly formed bone and residual material were performed for each stained section after 35 days using a software package (Image J 1.41, 


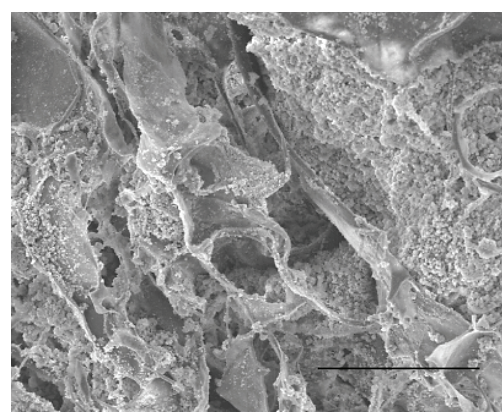

(a)

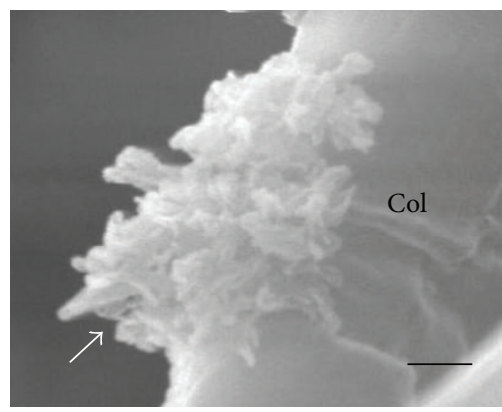

(d)

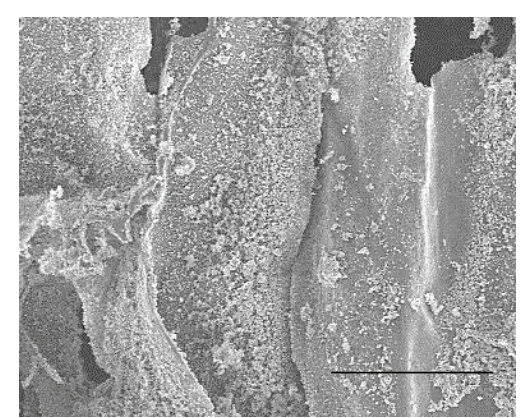

(b)

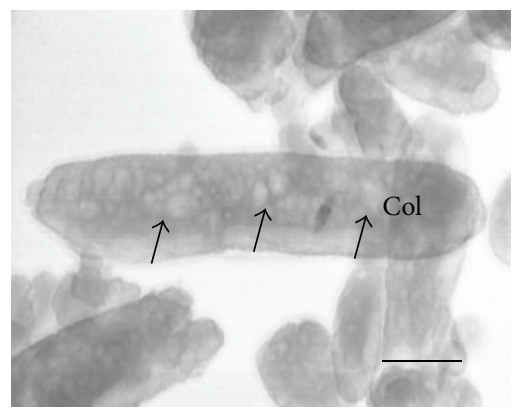

(e)

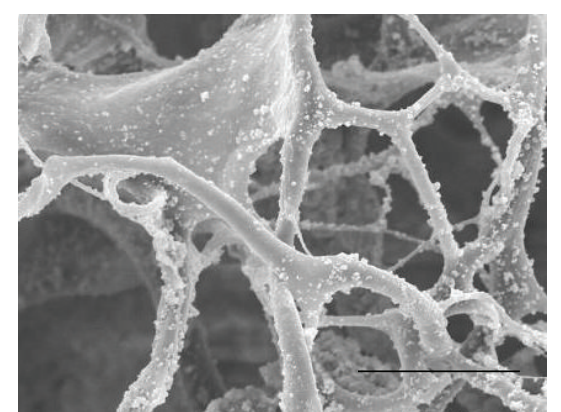

(c)

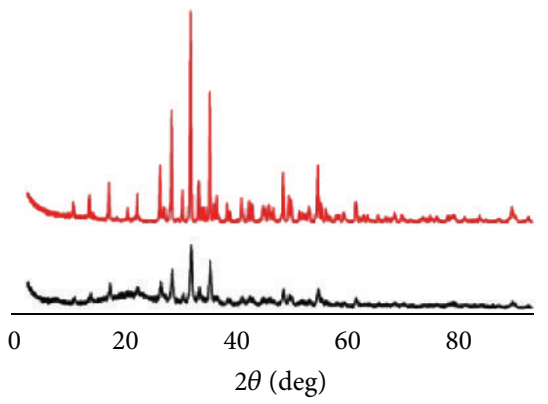

(A)

(B)

(f)

FIGURE 3: (a) SEM micrograph of the nano- $\beta$-TCP/collagen scaffold. (b) SEM micrograph on the inner surface of the nano- $\beta$-TCP/collagen scaffold. (c) Higher magnification of the nano- $\beta$-TCP/collagen scaffold. Dispersed $\beta$-TCP particles attached to fibers of collagen sponge. (d) Higher magnification of the nano- $\beta$-TCP/collagen scaffold. Aggregated forms of nano $\beta$-TCP particles are partly exhibited (arrow). (e) TEM micrograph of nano- $\beta$-TCP/collagen scaffold. Nano $\beta$-TCP particles are distinctly recognized (arrows). (f) XRD patterns of $\beta$-TCP (A) and nano- $\beta$-TCP/collagen scaffold (B). Abbreviations: Col, collagen sponge. Scale bars represent $100 \mu \mathrm{m}((\mathrm{a}),(\mathrm{b})), 10 \mu \mathrm{m}(\mathrm{c}), 200 \mathrm{~nm}(\mathrm{~d})$, and $100 \mathrm{~nm}(\mathrm{e})$.

National Institute of Health, Bethesda, MD, USA). The means and standard deviations of each parameter were calculated for each group.

Statistical analysis was performed using the MannWhitney $U$ test for porosity and compressive strength and Bonferroni's multiple comparison for CCK-8 assay and each histometric measurement. $P$ values $<0.05$ were considered statistically significant. All statistical procedures were performed using a software package (DR. SPSS 11.0, SPSS Japan, Tokyo, Japan).

\section{Results}

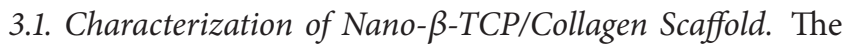
size range of nano- $\beta$-TCP particles was 20 to $500 \mathrm{~nm}$ and the mean particle size was $127 \mathrm{~nm}$ (Figures $1(\mathrm{c})$ and $1(\mathrm{e})$ ). From SEM and TEM observation, nanosized $\beta$-TCP particles attached to the surface of collagen sponge fibers (Figures 3(a), 3(b), 3(c), 3(d), and 3(e)). The nanobiomodified surface was also confirmed on the cross section of the material (Figure 3(b)). It could be observed that the sample consisted of well-dispersed particles; however, at higher magnification, particles were partly composed of many nanoscale particles of $\beta$-TCP, suggesting secondary particles, while aggregation
TABLE 1: Structural parameters of the material $(N=6$, mean \pm SD).

\begin{tabular}{lcc}
\hline & Collagen sponge & $\begin{array}{c}\text { Nano- } \beta- \\
\text { TCP/collagen } \\
\text { scaffold }\end{array}$ \\
\hline Porosity (\%) & $96.05 \pm 0.11$ & $95.89 \pm 0.05^{*}$ \\
Compressive strength $(\mathrm{MPa})$ & $0.11 \pm 0.02$ & $0.22 \pm 0.1^{*}$ \\
\hline
\end{tabular}

${ }^{*}$ Statistical difference compared to collagen sponge.

of nano- $\beta$-TCP was partially caused by the freeze-drying procedure (Figure $3(\mathrm{~d})$ ).

The porosity was calculated to be $>95 \%$ (Table 1 ). XRD investigations detected a peak profile of nano- $\beta$ TCP/collagen scaffold overlapped with the product of $\beta$-TCP powder (Figure 3(f)). The compressive strength of nano- $\beta$ TCP/collagen scaffold was approximately 2 -fold greater than that of the collagen sponge and this difference was statistically significant (Table 1).

3.2. Cytocompatibility of Nano- $\beta$-TCP/Collagen Scaffold. Osteoblastic MC3T3-E1 cells were significantly proliferated on the nano- $\beta$-TCP/collagen scaffold compared to the collagen sponge and the culture plate as control (Figure 4(a)). SEM observation revealed that cells attached to the collagen sponge coated with nano $\beta$-TCP. In addition, cell spreading 


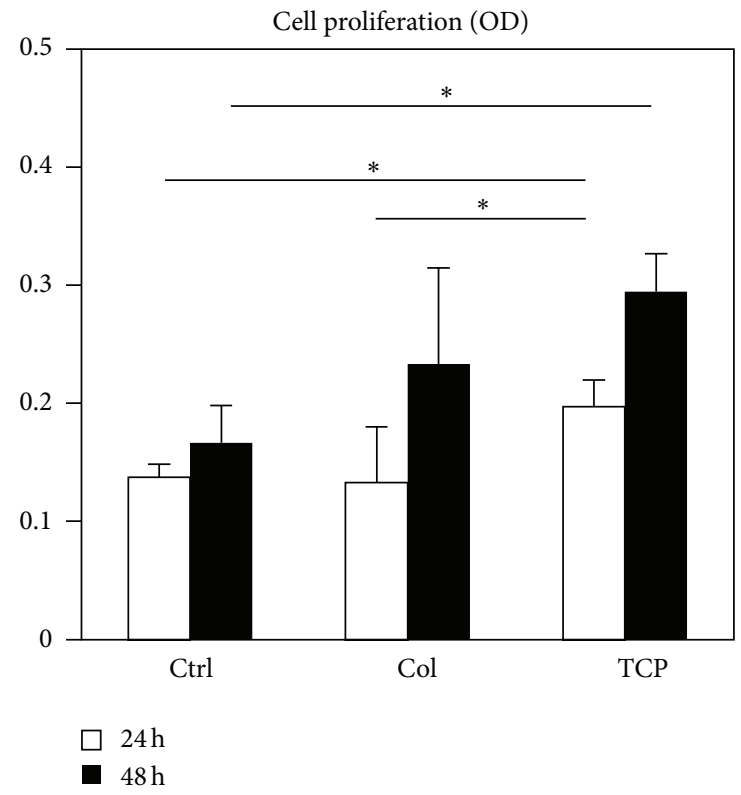

(a)

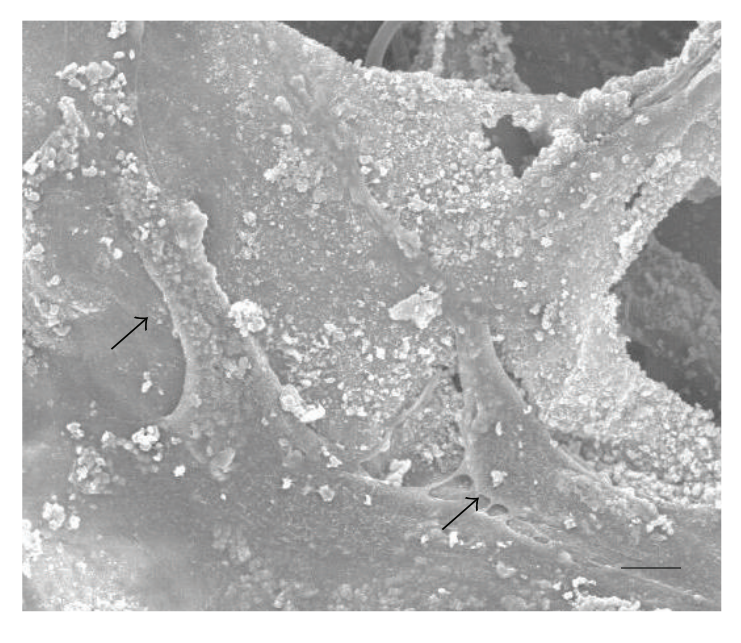

(b)

Figure 4: (a) CCK-8 assays of MC3T3-E1 cell proliferation after 24 and $48 \mathrm{~h}$ incubation $(N=6$, mean $\pm \mathrm{SD})$. Ctrl, Col, and TCP indicate control, collagen sponge, and nano- $\beta$-TCP/collagen scaffold, respectively. ${ }^{*} P<0.05$. (b) SEM micrograph of MC3T3-E1 cells seeded on the nano $\beta$-TCP/collagen scaffold after $24 \mathrm{~h}$ incubation. Cell spreading is shown on the scaffold (arrows). Scale bar represents $10 \mu \mathrm{m}$ (b).

with cell process elongation was also indicated, suggesting that nano- $\beta$-TCP/collagen scaffolds possess good cytocompatibility (Figure 4(b)).

3.3. Histological Observations at 10 Days. In the collagen sponge group, cell and tissue ingrowth was rarely demonstrated in implanted material. Furthermore, collagen sponge appeared to be considerably compressed and could not maintain the cell-invading and regenerative space (Figures 5(a) and 5(b)). Nano- $\beta$-TCP/collagen scaffolds caused various bioactivities in rat. Ingrowth of fibroblastic and osteoblastic cells and blood vessels was frequently observed at peripheral areas of implanted nano$\beta$-TCP/collagen (Figure 5(c)). Giant cells associated with resorption of materials appeared around the nanoparticle aggregates in the scaffold (Figure $5(d)$ ). Some inflammatory cells were seen around the residual material, indicating that the material possessed high biocompatibility. On the other hand, specimens receiving FGF2-loaded material provoked a more active tissue response. Formation of new bone as well as tissue ingrowth were prominently stimulated by FGF2 loading. New bone was composed of narrow trabeculae comprising osteoblasts and osteocytes (Figures 5(e), 5(f), 5(g), and 5(h)).

3.4. Histological Observations at 35 Days. Histological specimens with only collagen sponge exhibited evidence of residual material (Figure 6(a)). Slight cell infiltration in the inner side of the residual collagen sponge was observed, suggesting low degradation and tissue replacement of collagen sponge by remodeling processes (Figure 6(b)). New bone augmentation frequently occurred by the application of nano- $\beta$-TCP/collagen scaffold (Figure 6(c)). Although some residual large particles of $\beta$-TCP were observed in the newly augmented bone, most of the collagen sponge scaffolds had disappeared compared to collagen sponge group (Figure 6(d)). It seems likely that degradability of collagen sponge was promoted by the application of nano- $\beta$-TCP coating. In the FGF2-receiving group, considerable bone formation continuous with the preexisting bone was clearly detectable (Figures 6(e) and 6(g)). However, evidence of residual grafted material was slightly observed in the group of collagen sponge in combination with FGF2 (Figure 6(f)). In contrast, in the control, there was little evidence of bone augmentation (Figure 6(h)).

3.5. Histomorphometric Analysis. The degree of bone augmentation after implantation of each material is presented in Figures 7(a) and 7(b). In specimens that received nano$\beta$-TCP/collagen, bone augmentation was significantly accelerated at 35 days, approximately 1.5 -fold greater than that of the control. FGF2-loaded materials also significantly stimulated bone formation compared to nonloading. Nano- $\beta$ TCP/collagen in combination with FGF2 had the highest osteoconductivity among all groups. Regarding bone height measurement, a significant difference was found between the application of scaffolds with and without FGF2. From these results, biological function of nanoparticles of $\beta$-TCP would be expected to be exerted under FGF2 application.

The amount of residual material in histological specimens is shown in Figures 7(c) and 7(d). The area of residual nano$\beta$-TCP/collagen scaffold was significantly lower compared to 


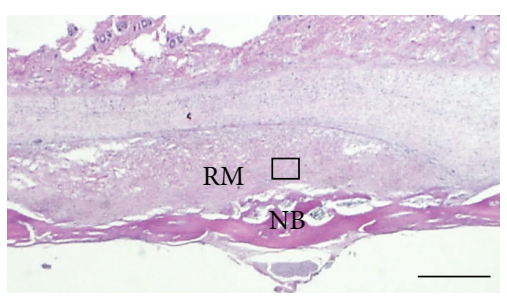

(a)

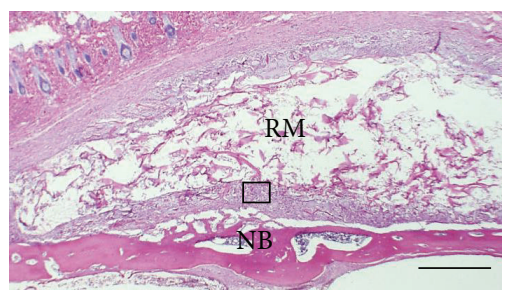

(c)

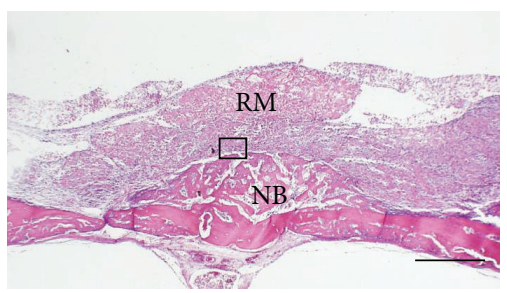

(e)

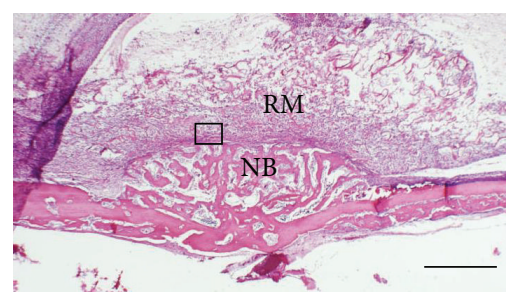

(g)

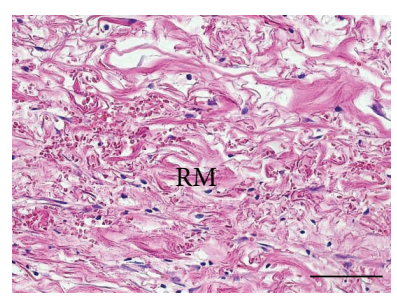

(b)

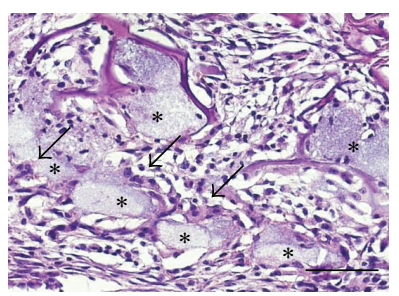

(d)

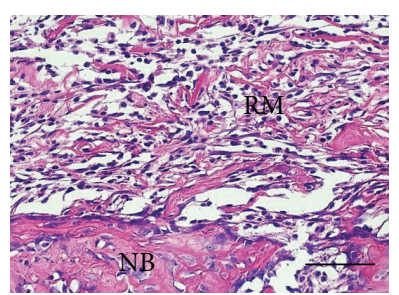

(f)

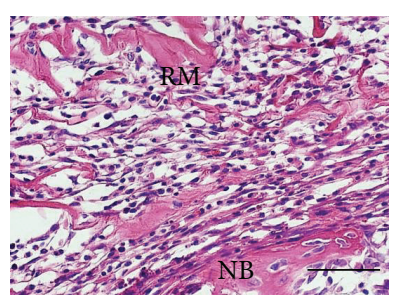

(h)

FIGURE 5: Histological findings at 10 days. (a) Specimen receiving collagen sponge application. Cell and tissue ingrowth were rarely demonstrated in the collagen sponge. (b) Higher magnification of the framed area in (a). Collagen sponge was frequently compressed on the cranial bone. (c) Specimen receiving implantation of the nano- $\beta$-TCP/collagen scaffold. Ingrowth of regenerative tissue was observed at peripheral areas of implanted nano- $\beta$-TCP/collagen scaffolds on the skull of the rat. (d) Higher magnification of the framed area in (c). Macrophage-like cells (arrows) appeared around the agglutination of $\beta$-TCP particles (asterisks) of the scaffold. (e) Specimen receiving FGF2loaded collagen sponge. New bone augmentation was highly promoted. (f) Higher magnification of the framed area in (e). Osteoblasts and osteocytes were found in newly formed woven bone. (g) Specimen receiving FGF2-loaded nano $\beta$-TCP/collagen scaffold. Formation of new bone as well as tissue ingrowth was prominently stimulated. (h) Higher magnification of the framed area in (g). Residual material was fractionated by newly formed connective tissue. Development of trabecular bone containing osteoblasts was evident. Abbreviations: NB, new bone; RM, residual material. Scale bars represent $1 \mathrm{~mm}$ ((a), (c), (e), (g)) and $100 \mu \mathrm{m}$ ((b), (d), (f), (h)). Staining: HE.

that of residual collagen sponge, suggesting that the former scaffold exhibited high biodegradability. Addition of FGF2 to each material stimulated material resorption. Regarding the height of residual material, there were no significant differences among all groups. Samples coated with a nano-TCP dispersion showed a tendency to increased degradation after implantation, regardless of FGF2 loading.

\section{Discussion}

The present study focused on the effects of nanobioceramic coating of biomaterials for developing an osteoconductive scaffold. Histological findings revealed that the nano $\beta$ TCP-coated scaffold enhanced augmentation of rat cranial bone. It was known that $\beta$-TCP has the potential to induce osteoconductivity in animal and human studies $[31,32]$. Recently, many investigators have demonstrated that implanted $\beta$-TCP is resorbed by macrophagelike cells without cytotoxicity or inflammatory response $[33,34]$. $\beta$-TCP degradation promotes concentration of calcium ions released into the regenerative space and alkaline phosphatase activity of osteoblastic cells [35, 36]; these phenomena allow environmental changes for osteogenesis to occur. Histological specimens treated with the 


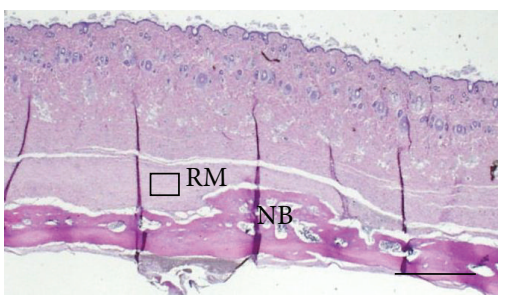

(a)

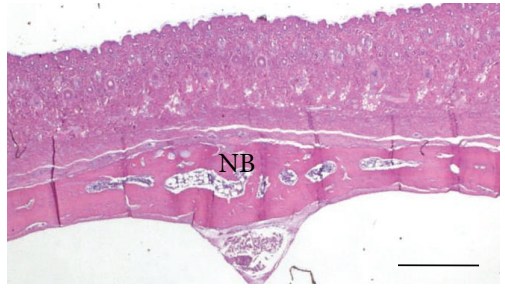

(c)

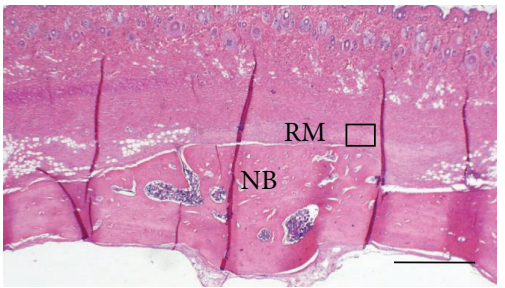

(e)

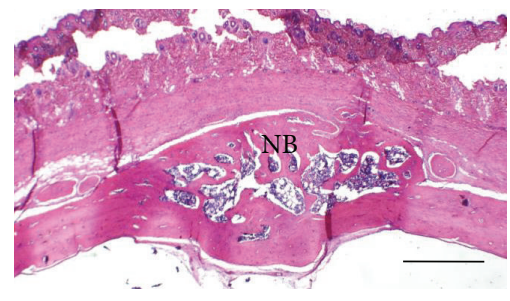

(g)

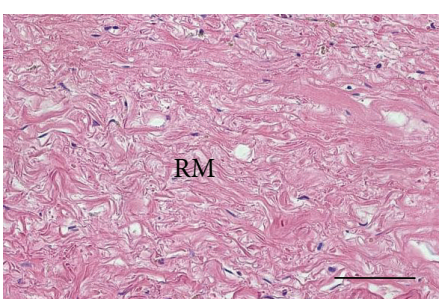

(b)

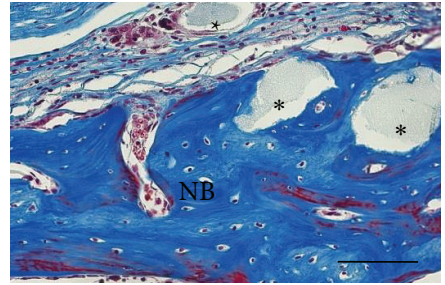

(d)

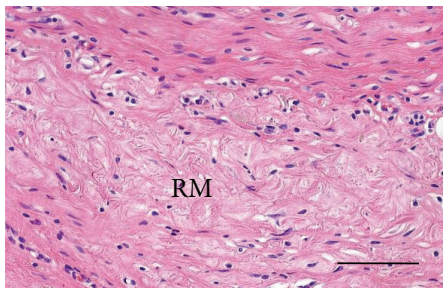

(f)

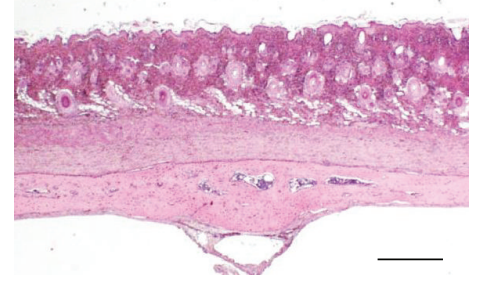

(h)

Figure 6: Histological findings at 35 days. (a) Group of collagen sponge implantation. Bone formation was localized near the preexisting bone, whereas residual material was obviously evident on the cranial bone. (b) Higher magnification of the framed area in (a). Cell ingrowth was sparse in the collagen sponge. (c) Specimen receiving implantation of nano $\beta$-TCP/collagen scaffold. New bone augmentation occurred and residual material was rarely observed. (d) Higher magnification of histological section with nano- $\beta$-TCP/collagen scaffold implantation. Residual large aggregation of $\beta$-TCP (asterisks) was mildly observed in newly formed bone and connective tissue. (e) Specimen receiving FGF2-loaded collagen sponge. Bone augmentation was observed at the material implantation area. (f) Higher magnification of framed area of (e). Residual collagen sponge was slightly detected in the connective tissue around the newly formed bone. (g) Specimen receiving FGF2loaded nano- $\beta$-TCP/collagen scaffold. Advanced bone formation was demonstrated similarly to the FGF2-loaded collagen sponge. However, residual implanted material was scarcely detectable. (h) Control. There was little evidence of bone augmentation. Abbreviations: NB, new bone; RM, residual material. Scale bars represent $1 \mathrm{~mm}$ ((a), (c), (e), (g), (h)) and $100 \mu \mathrm{m}((\mathrm{b}),(\mathrm{d}),(\mathrm{f}))$. Staining: HE ((a)-(c), (e)-(h)) and Masson's trichrome (d).

nano-TCP scaffold at 10 days revealed foreign-body giant cells around the relatively large particles of $\beta$-TCP in the scaffold. Although the particle size of $\beta$-TCP covers a wide range, large particles might be resorbed by macrophages while small particles would be dissolved in tissue fluid at the early healing stage. It seems likely that bone augmentation was facilitated by providing early a high concentration of mineralizing elements from nano-TCP degradation, compared to conventional TCP-only grafting materials. On the other hand, the long-term residue of bioceramics absolutely prevented active tissue remodeling, resulting in immature tissue reformation $[37,38]$. $\beta$-TCP also remained for a long period in the healing tissue $[10,11]$. However, we found in this examination at 35 days that residual $\beta$-TCP particles were rarely seen in the regenerative tissue. Interestingly, 35day specimens displayed residual collagen sponge, but the collagen composition in the nano- $\beta$-TCP/collagen scaffold synchronously disappeared with degradation of nano $\beta$ TCP particles. Further evidence that resorption of nano$\beta$-TCP/ collagen was significantly greater than that of collagen sponge being given by the histological measurements. Conceivably, the base material, collagen modified by 


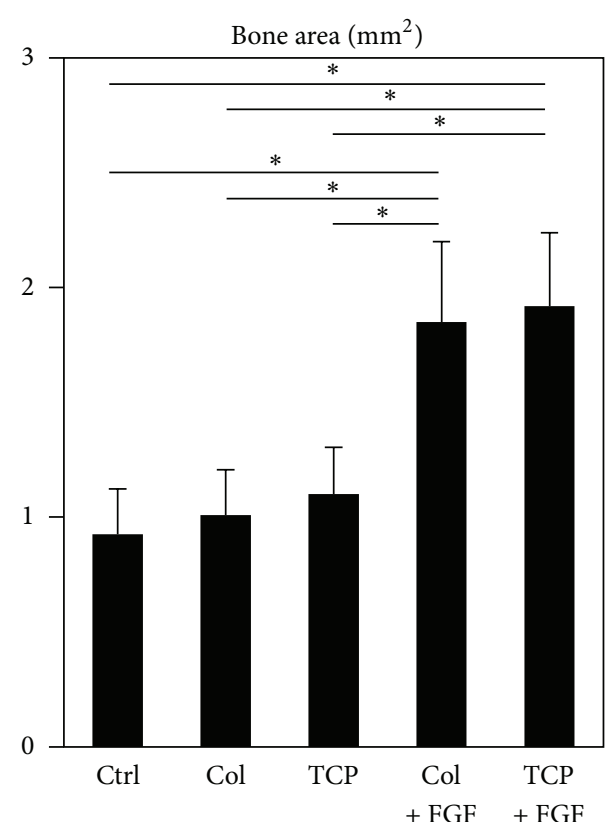

(a)

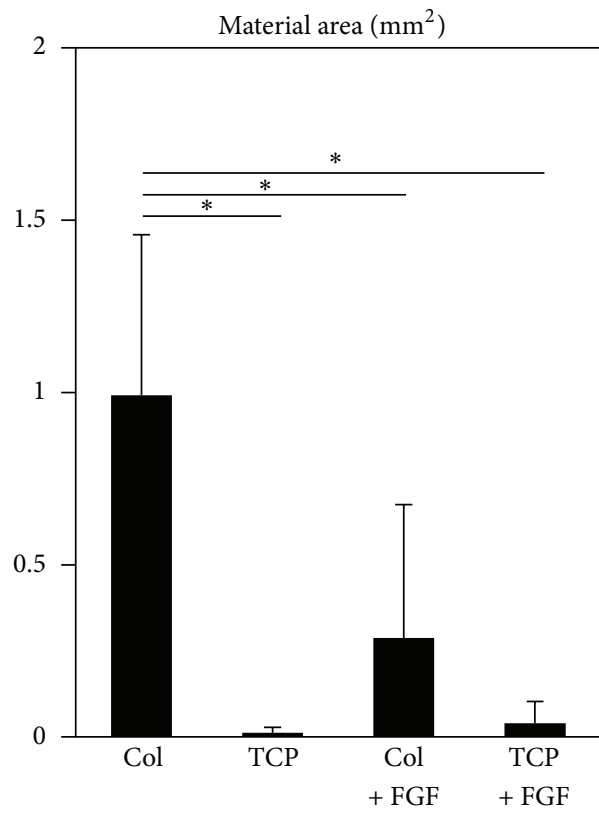

(c)

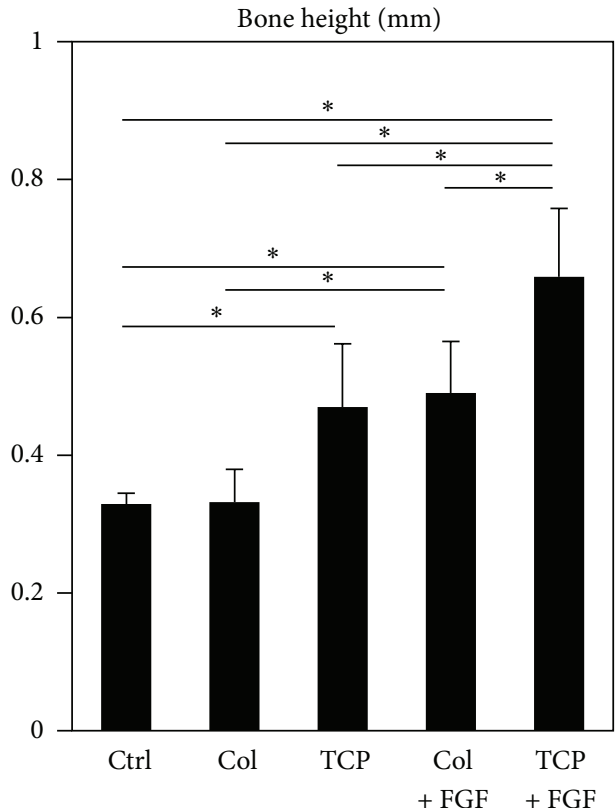

(b)

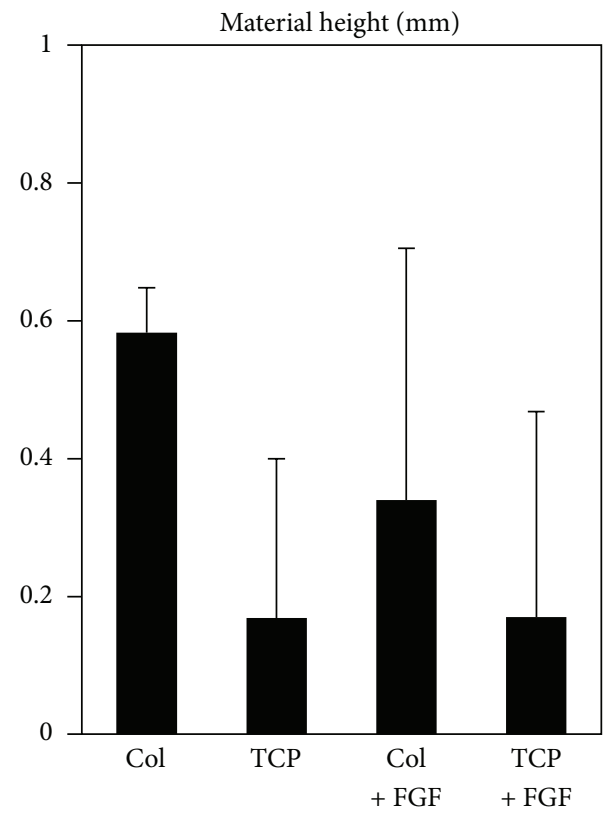

(d)

Figure 7: Histomorphometric analysis at 35 days $(N=8$, mean \pm SD). (a) New bone area. (b) New bone height. (c) Residual material area. (d) Residual material height. Ctrl, Col, TCP, Col + FGF and TCP + FGF, indicate control, collagen sponge, nano- $\beta$-TCP/collagen scaffold, FGF2/collagen sponge, and FGF2/nano- $\beta$-TCP/collagen scaffold, respectively. ${ }^{*} P<0.05$.

nano- $\beta$-TCP, was simultaneously phagocytosed by macrophages activated by the effect of nano-TCP application. Therefore, the coating procedure using the nanosized ceramic substance lent tissue-replacing activity to the collagen sponge as well as osteoconductivity. In vivo regulation of material degradation possibly leads to the controlled release of medicine and growth factors, and a process of selective tissue rebuilding. Therefore, it will be necessary to elucidate the mechanisms regarding the degree of nano- $\beta$-TCP application associated with biological degradation.

The mechanical properties of the regenerative scaffold play a facilitative role in maintaining the regenerative space following application in the body [1]. It was revealed that the compressive strength of collagen sponge was reinforced by coating with a nano $\beta$-TCP dispersion. Ordinarily, design of regenerative scaffolds requires a highly porous structure 
for cell invasion and proliferation; however, a higher porosity of biomaterial causes lower mechanical strength [39]. Nanomodification of $\beta$-TCP will provide advantages for tissue engineering, such as physical properties and porosity, based on current evidence. In SEM images, collagen sponge foam coated with a nano $\beta$-TCP dispersion did not fill the inner space with nanoceramic particles, the maintaining cell infiltration area, indicating that high porosity of the scaffold was exhibited. At 10 days after implantation of the nano- $\beta$-TCP/collagen scaffold, cells that invaded into the scaffold were noted. Furthermore, sufficient regenerative space was displayed by implantation of this scaffold compared to collagen sponge.

As to the reason for promoting cell migration and material degradability, we speculated that collagen sponge coated with nanoparticles would have the property of protein adsorption as well as a physical effect. Recent studies demonstrated that various types of nanoparticle promote protein adsorption and cell adhesion $[40,41]$. Nanomaterials would be beneficial in the healing of tissue because the regenerative space could retain several growth, differentiation, and nutritional factors that promote cell activity and tissue healing. Consistently, FGF2 application significantly assured stimulation of bone augmentation, although there was a significant difference between FGF-loaded samples with nano- $\beta$-TCP coating and without coating. We speculate that different biological effects are involved in nano- $\beta$-TCP coating such as supplementary regulation of osteoconductive function and adsorption of FGF2 molecules. Eventually, we found dramatic effects of FGF2 on woven bone formation at 10 days and rapid degradation of FGF2-loaded samples. These findings are consistent with the mechanisms supported by previous studies, in which FGF2 was shown to promote cell proliferation [42], vascularization [43], and wound healing $[44,45]$. The combination use of FGF2 and nano- $\beta$-TCP as a well-degradable and osteoconductive scaffold presumably facilitated the wound healing associated with bone tissue engineering.

The biocompatibility of nanomaterials is an important problem; however, evaluation of a systematic testing method of safety for nanomaterials is not currently established. In this study, we evaluated biocompatibility in vitro and in vivo through proliferation assay, SEM observation, and histopathologic evaluation of scaffolds. After cell seeding, good cell viability and spreading on the sample were confirmed. By histological observation, inflammatory cells were rarely seen around the nano-modified sample. Based on this evidence, we propose that the nano- $\beta$-TCP/collagen scaffold has good biocompatibility. In addition, collagen sponge, consisting of atelocollagen, was recognized as a compatible material [46, 47]. Recently, many studies have demonstrated the high compatibility of nanobioceramics in vitro [48, 49]. On the other hand, intravenous injection of nanohydroxyapatite resulted in vacuolar degeneration of nephric tubule epithelium, indicating that size of particle might play a significant role in biocompatibility [50]. Furthermore, there was evidence of long-term residue of nonabsorbable nanomaterials in the cell lysosomes following phagocytosis [51]. Although aberrant healing was not detected in this study, negative biological action resulting from nanomaterial use is an important point to be considered in the future.

\section{Conclusion}

Collagen scaffolds coated with a nano- $\beta$-TCP dispersion displayed good biocompatibility and osteoconductivity. FGF2loaded nano- $\beta$-TCP/collagen scaffold had the highest boneforming effects. Moreover, degradation of the material was accelerated by modification of the nano- $\beta$-TCP application regardless of FGF2 loading. The bioactivity of nano- $\beta$ $\mathrm{TCP} /$ collagen scaffolds has thus proved to be useful as a biomaterial for rebuilding and regenerating bone tissue.

\section{Acknowledgments}

The authors are grateful to their colleagues, Dr. Kana Inoue, Dr. Yuta Kosen, Ms. Izumi Kanayama, and Mr. Takashi Yoshida, for their assistance. The authors thank Olympus Terumo Biomaterials Corp. for providing the collagen sponge and Tomita Pharmaceutical Co., Ltd., for providing the $\beta$ TCP. This work was supported by JPSP KAKENHI Grant no. 22791916. The authors report no conflict of interests related to this study. This paper was presented as an examination thesis at Hokkaido University.

\section{References}

[1] F.-M. Chen and Y. Jin, "Periodontal tissue engineering and regeneration: current approaches and expanding opportunities," Tissue Engineering B, vol. 16, no. 2, pp. 219-255, 2010.

[2] H. Yuan, C. A. van Blitterswijk, K. de Groot, and J. D. de Bruijn, "Cross-species comparison of ectopic bone formation in biphasic calcium phosphate (BCP) and hydroxyapatite (HA) scaffolds," Tissue Engineering, vol. 12, no. 6, pp. 1607-1615, 2006.

[3] H. Yuan, M. van den Doel, S. Li, C. A. van Blitterswijk, K. de Groot, and J. D. de Bruijn, "A comparison of the osteoinductive potential of two calcium phosphate ceramics implanted intramuscularly in goats," Journal of Materials Science, vol. 13, no. 12, pp. 1271-1275, 2002.

[4] J. E. Gough, J. R. Jones, and L. L. Hench, "Nodule formation and mineralisation of human primary osteoblasts cultured on a porous bioactive glass scaffold," Biomaterials, vol. 25, no. 11, pp. 2039-2046, 2004.

[5] M. Vallet-Regí and E. Ruiz-Hernández, "Bioceramics: from bone regeneration to cancer nanomedicine," Advanced Materials, vol. 23, no. 44, pp. 5177-5218, 2011.

[6] G. Daculsi, "Biphasic calcium phosphate concept applied to artificial bone, implant coating and injectable bone substitute," Biomaterials, vol. 19, no. 16, pp. 1473-1478, 1998.

[7] A. Ogose, T. Hotta, H. Kawashima et al., "Comparison of hydroxyapatite and beta tricalcium phosphate as bone substitutes after excision of bone tumors," Journal of Biomedical Materials Research B, vol. 72, no. 1, pp. 94-101, 2005.

[8] L. Nie, D. Chen, J. Suo et al., "Physicochemical characterization and biocompatibility in vitro of biphasic calcium phosphate/polyvinyl alcohol scaffolds prepared by freeze-drying method for bone tissue engineering applications," Colloids and Surfaces B, vol. 100, pp. 169-176, 2012. 
[9] D. P. Sarment, J. W. Cooke, S. E. Miller et al., "Effect of rhPDGF$\mathrm{BB}$ on bone turnover during periodontal repair," Journal of Clinical Periodontology, vol. 33, no. 2, pp. 135-140, 2006.

[10] Y. Oi, M. Ota, S. Yamamoto, Y. Shibukawa, and S. Yamada, " $\beta$-tricalcium phosphate and basic fibroblast growth factor combination enhances periodontal regeneration in intrabony defects in dogs," Dental Materials Journal, vol. 28, no. 2, pp. 162$169,2009$.

[11] R. D. A. Gaasbeek, H. G. Toonen, R. J. van Heerwaarden, and P. Buma, "Mechanism of bone incorporation of $\beta$-TCP bone substitute in open wedge tibial osteotomy in patients," Biomaterials, vol. 26, no. 33, pp. 6713-6719, 2005.

[12] A. Stavropoulos, P. Windisch, D. Szendröi-Kiss, R. Peter, I. Gera, and A. Sculean, "Clinical and histologic evaluation of granular beta-tricalcium phosphate for the treatment of human intrabony periodontal defects: a report on five cases," Journal of Periodontology, vol. 81, no. 2, pp. 325-334, 2010.

[13] R. Fujita, A. Yokoyama, T. Kawasaki, and T. Kohgo, "Bone augmentation osteogenesis using hydroxyapatite and $\beta$-tricalcium phosphate blocks," Journal of Oral and Maxillofacial Surgery, vol. 61, no. 9, pp. 1045-1053, 2003.

[14] T. Tanaka, Y. Kumagae, M. Saito et al., "Bone formation and resorption in patients after implantation of $\beta$-tricalcium phosphate blocks with $60 \%$ and $75 \%$ porosity in opening-wedge high tibial osteotomy," Journal of Biomedical Materials Research $B$, vol. 86, no. 2, pp. 453-459, 2008.

[15] A. E. Nel, L. Mädler, D. Velegol et al., "Understanding biophysicochemical interactions at the nano-bio interface," Nature Materials, vol. 8, no. 7, pp. 543-557, 2009.

[16] I. Lynch, T. Cedervall, M. Lundqvist, C. Cabaleiro-Lago, S. Linse, and K. A. Dawson, "The nanoparticle-protein complex as a biological entity; a complex fluids and surface science challenge for the 21st century," Advances in Colloid and Interface Science, vol. 134-135, pp. 167-174, 2007.

[17] F. Zhang, J. Chang, K. Lin, and J. Lu, "Preparation, mechanical properties and in vitro degradability of wollastonite/tricalcium phosphate macroporous scaffolds from nanocomposite powders," Journal of Materials Science, vol. 19, no. 1, pp. 167-173, 2008.

[18] B. Li, X. Liao, L. Zheng et al., "Effect of nano structure on osteoinduction of porous biphasic calcium phosphate ceramics," Acta Biomaterialia, vol. 8, no. 10, pp. 3794-3804, 2012.

[19] F. Watari, N. Takashi, A. Yokoyama et al., "Material nanosizing effect on living organisms: non-specific, biointeractive, physical size effects," Journal of the Royal Society Interface, vol. 6, no. 3, pp. S371-S388, 2009.

[20] X. Ling, W. Chen, S. Liu, and G. Wang, "Expression of TGFbeta in region of bone defect repaired by collagen/nano-betatricalcium phosphate composite artificial bone," Journal of Huazhong University of Science and Technology, vol. 23, no. 3, pp. 302-305, 2003.

[21] M. Ebrahimi, P. Pripatnanont, N. Monmaturapoj, and S. Suttapreyasri, "Fabrication and characterization of novel nano hydroxyapatite/ $\beta$-tricalcium phosphate scaffolds in three different composition ratios," Journal of Biomedical Materials Research A, vol. 100, no. 9, pp. 2260-2268, 2012.

[22] B. Fugetsu, W. Han, N. Endo, Y. Kamiya, and T. Okuhara, "Disassembling single-walled carbon nanotube bundles by dipole/dipole electrostatic interactions," Chemistry Letters, vol. 34, no. 9, pp. 1218-1219, 2005.

[23] H. Yu and B. Fugetsu, "A novel adsorbent obtained by inserting carbon nanotubes into cavities of diatomite and applications for organic dye elimination from contaminated water," Journal of Hazardous Materials, vol. 177, no. 1-3, pp. 138-145, 2010.

[24] A. F. von Recum, C. E. Shannon, C. E. Cannon, K. J. Long, T. G. Van Kooten, and J. Meyle, "Surface roughness, porosity, and texture as modifiers of cellular adhesion," Tissue Engineering, vol. 2, no. 4, pp. 241-253, 1996.

[25] K. Webb, V. Hlady, and P. A. Tresco, "Relative importance of surface wettability and charged functional groups on NIH 3 T3 fibroblast attachment, spreading, and cytoskeletal organization," Journal of Biomedical Materials Research, vol. 41, no. 3, pp. 422-430, 1998.

[26] Y. R. Yun, J. E. Won, E. Jeon et al., "Fibroblast growth factors: biology, function, and application for tissue regeneration," Journal of Tissue Engineering and Regenerative Medicine, vol. 1, Article ID 218142, 2010.

[27] Y. Tabata, K. Yamada, L. Hong, S. Miyamoto, N. Hashimoto, and Y. Ikada, "Skull bone regeneration in primates in response to basic fibroblast growth factor," Journal of Neurosurgery, vol. 91, no. 5, pp. 851-856, 1999.

[28] N. Kobayashi, H. Miyaji, T. Sugaya, and M. Kawanami, "Bone augmentation by implantation of an FGF2-loaded collagen gelsponge composite scaffold," Journal of Oral Tissue Engineering, vol. 8, no. 2, pp. 91-101, 2010.

[29] S. Takayama, S. Murakami, Y. Shimabukuro, M. Kitamura, and H. Okada, "Periodontal regeneration by FGF-2 (bFGF) in primate models," Journal of Dental Research, vol. 80, no. 12, pp. 2075-2079, 2001.

[30] M. Kitamura, M. Akamatsu, M. MacHigashira et al., "FGF-2 stimulates periodontal regeneration: results of a multi-center randomized clinical trial," Journal of Dental Research, vol. 90, no. 1, pp. 35-40, 2011.

[31] H. Yuan, Z. Yang, J. D. de Bruijn, K. de Groot, and X. Zhang, "Material-dependent bone induction by calcium phosphate ceramics: a 2.5-year study in dog," Biomaterials, vol. 22, no. 19, pp. 2617-2623, 2001.

[32] A. Ogose, N. Kondo, H. Umezu et al., "Histological assessment in grafts of highly purified beta-tricalcium phosphate (OSferion) in human bones," Biomaterials, vol. 27, no. 8, pp. 1542$1549,2006$.

[33] M. Nagayama, H. Takeuchi, and Y. Doi, "Comparison of carbonate apatite and $\beta$-tricalcium phosphate (resorbable calcium phosphates) implanted subcutaneously into the back of rats," Dental Materials Journal, vol. 25, no. 2, pp. 219-225, 2006.

[34] N. Kondo, A. Ogose, K. Tokunaga et al., "Bone formation and resorption of highly purified $\beta$-tricalcium phosphate in the rat femoral condyle," Biomaterials, vol. 26, no. 28, pp. 5600-5608, 2005.

[35] L. Xia, Z. Zhang, L. Chen et al., "Proliferation and osteogenic differentiation of human periodontal ligament cells on akermanite and $\beta$-TCP bioceramics," European Cells and Materials, vol. 22, pp. 68-83, 2011.

[36] R. Detsch, H. Mayr, and G. Ziegler, "Formation of osteoclastlike cells on HA and TCP ceramics," Acta Biomaterialia, vol. 4, no. 1, pp. 139-148, 2008.

[37] H. Yuan, Z. Yang, Y. Li, X. Zhang, J. D. De Bruijn, and K. De Groot, "Osteoinduction by calcium phosphate biomaterials," Journal of Materials Science, vol. 9, no. 12, pp. 723-726, 1998.

[38] S. Hasegawa, J. Tamura, M. Neo et al., "In vivo evaluation of a porous hydroxyapatite/poly-DL-lactide composite for use as a bone substitute," Journal of Biomedical Materials Research A, vol. 75, no. 3, pp. 567-579, 2005. 
[39] S. Bose, J. Darsell, M. Kintner, H. Hosick, and A. Bandyopadhyay, "Pore size and pore volume effects on alumina and TCP ceramic scaffolds," Materials Science and Engineering C, vol. 23, no. 4, pp. 479-486, 2003.

[40] K. M. Woo, V. J. Chen, and P. X. Ma, "Nano-fibrous scaffolding architecture selectively enhances protein adsorption contributing to cell attachment," Journal of Biomedical Materials Research A, vol. 67, no. 2, pp. 53153-53157, 2003.

[41] G. Wei and P. X. Ma, "Structure and properties of nanohydroxyapatite/polymer composite scaffolds for bone tissue engineering," Biomaterials, vol. 25, no. 19, pp. 4749-4757, 2004.

[42] P. Kettunen, I. Karavanova, and I. Thesleff, "Responsiveness of developing dental tissues to fibroblast growth factors: expression proliferation by FGF-2, $-4,-8$, and -9, , Developmental Genetics, vol. 22, no. 4, pp. 374-385, 1998.

[43] A. Hayek, F. L. Culler, G. M. Beattie, A. D. Lopez, P. Cuevas, and A. Baird, "An in vivo model for study of the angiogenic effects of basic fibroblast growth factor," Biochemical and Biophysical Research Communications, vol. 147, no. 2, pp. 876-880, 1987.

[44] N. T. Bennett and G. S. Schultz, "Growth factors and wound healing: biochemical properties of growth factors and their receptors," American Journal of Surgery, vol. 165, no. 6, pp. 728737, 1993.

[45] N. T. Bennett and G. S. Schultz, "Growth factors and wound healing: part II. Role in normal and chronic wound healing," American Journal of Surgery, vol. 166, no. 1, pp. 74-81, 1993.

[46] S. Shimoji, H. Miyaji, T. Sugaya et al., "Bone perforation and placement of collagen sponge facilitate bone augmentation," Journal of Periodontology, vol. 80, no. 3, pp. 505-511, 2009.

[47] Y. Kosen, H. Miyaji, A. Kato, T. Sugaya, and M. Kawanami, "Application of collagen hydrogel/sponge scaffold facilitates periodontal wound healing in class II furcation defects in beagle dogs," Journal of Periodontal Research, vol. 47, no. 5, pp. 626634, 2012.

[48] Z. Shi, X. Huang, Y. Cai, R. Tang, and D. Yang, "Size effect of hydroxyapatite nanoparticles on proliferation and apoptosis of osteoblast-like cells," Acta Biomaterialia, vol. 5, no. 1, pp. 338345, 2009.

[49] J. Scheel, S. Weimans, A. Thiemann, E. Heisler, and M. Hermann, "Exposure of the murine RAW 264.7 macrophage cell line to hydroxyapatite dispersions of various composition and morphology: assessment of cytotoxicity, activation and stress response," Toxicology In Vitro, vol. 23, no. 3, pp. 531-538, 2009.

[50] D. Tingting, X. Yang, L. Hua, H. Zhewei, and S. Jiao, "Effect of particle size of hydroxyapatite nanoparticles on its biocompatibility," Transactions on Nanobioscience, vol. 11, no. 4, pp. 336340, 2012.

[51] K. Wang, J. Ruan, H. Song et al., "Biocompatibility of graphene oxide," Nanoscale Research Letters, vol. 6, article 8, 2011. 

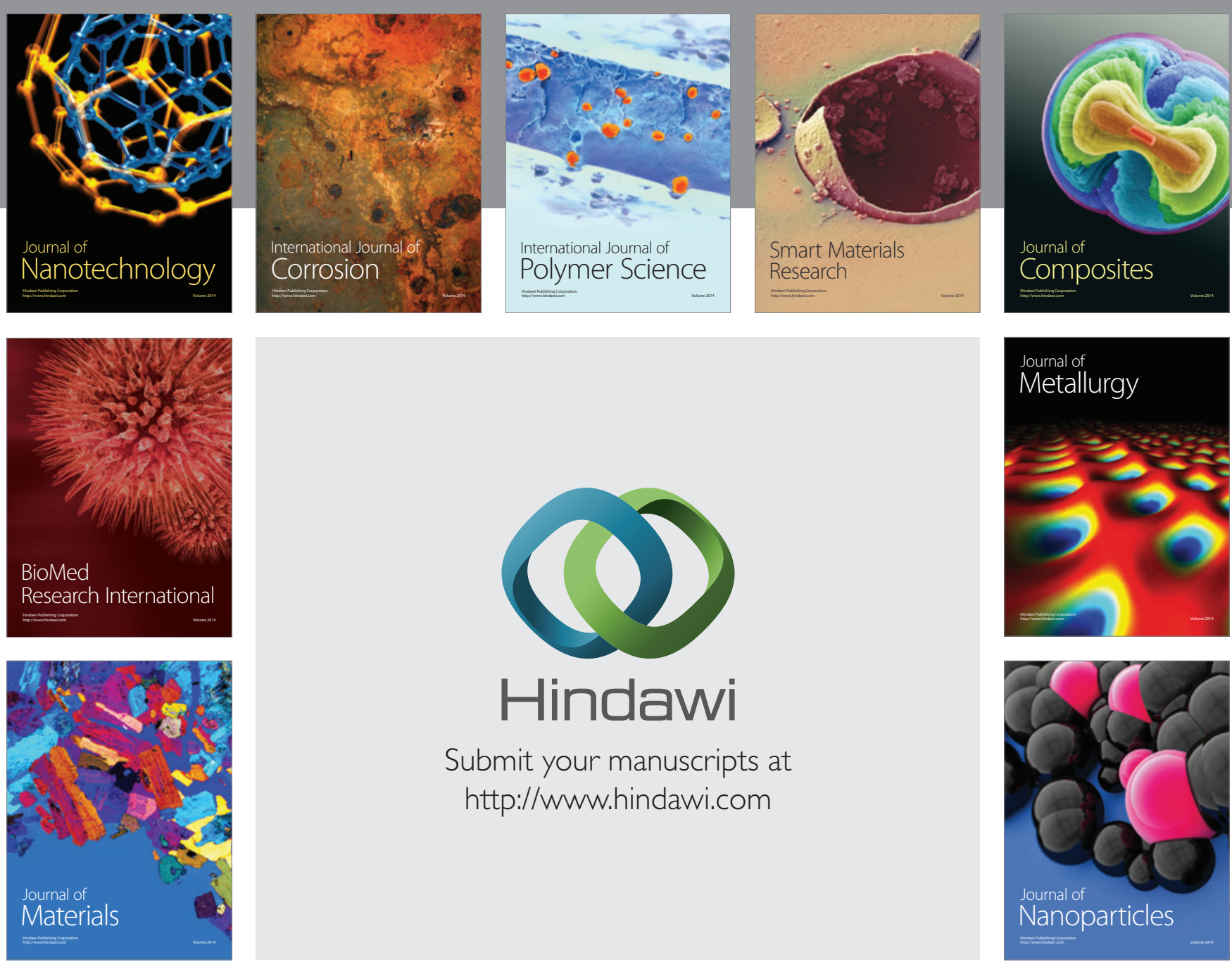

Submit your manuscripts at http://www.hindawi.com
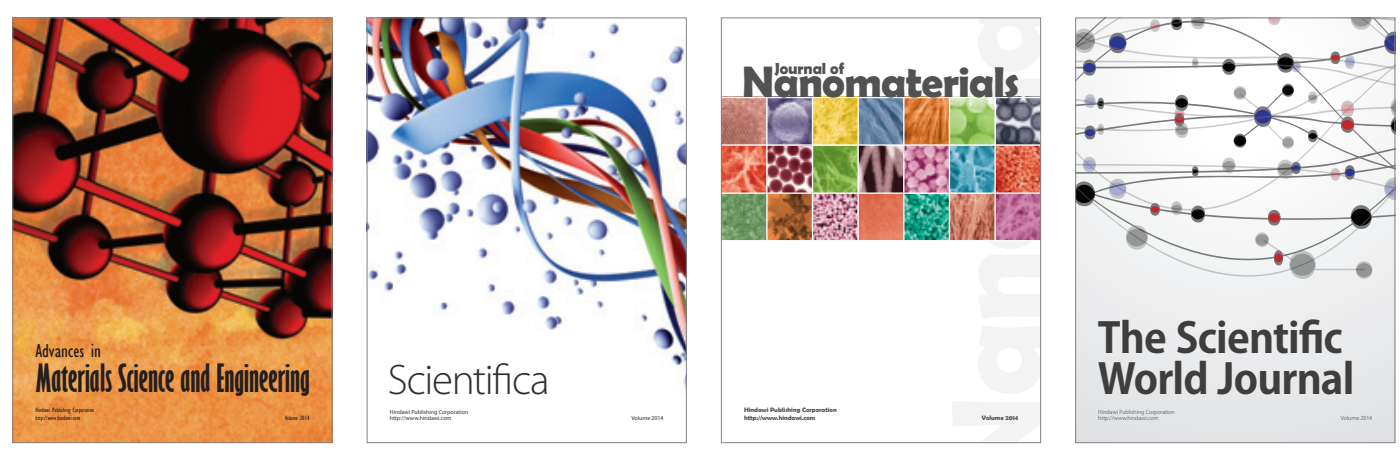

\section{The Scientific World Journal}
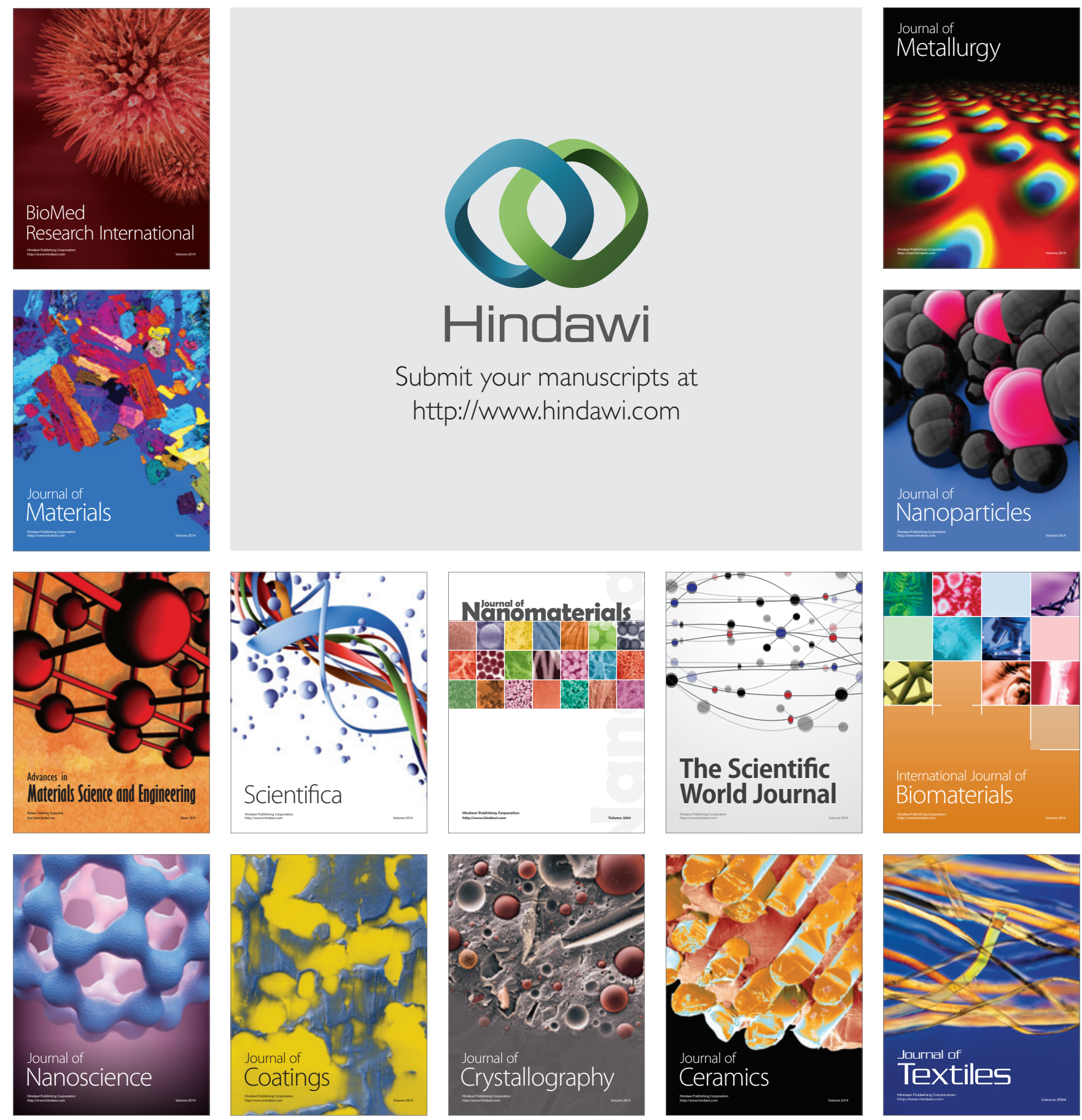